\title{
TRAJETÓRIA, DOCÊNCIA E MEMÓRIAS DE UMA PROFESSORA: FRAGMENTOS DO ENSINO RURAL EM NOVO HAMBURGO/RS 1940-1969 ${ }^{1}$
}

\author{
José Edimar de Souza ${ }^{2}$ \\ Fundação Escola Técnica Liberato Salzano Vieira da Cunha - Brasil \\ Grupo de Pesquisa: HISULA \\ profedimar@gmail.com
}

Recepción: $21 / 02 / 2012$

Evaluación: 20/03/2012

Aceptación: 29/05/2012

Artículo de Reflexión

doi: 10,9757

\section{RESUMO}

O objetivo deste estudo centra-se nos fatos e reflexões sobre o ensino da história de um professor de escola primária, cuja carreira se desenvolveu em áreas rurais de Novo Hamburgo/ RS entre 1940 e 1969. Este estudo está diretamente relacionado com a pesquisa mais ampla, que lida com as trajetórias de sujeitos professores que constituíram docente em classes multisseriadas nas escolas públicas de Novo Hamburgo, no campo, no contexto de tempo prolongado (1940 e 2009). Neste trabalho em particular, a partir da reflexão sobre o ensino em diferentes localidades de Lomba Grande, atravessados por uma professora - Gersy - no desenvolvimento de sua prática, com foco na sua história, tecida nas aulas de ensino rural. A pesquisa é qualitativa, utilizando a metodologia da história oral, com algumas entrevistas semi-estruturadas. O referencial teórico baseia-se na perspectiva da história cultural, e memórias como um documento. A professora em questão, ainda muito jovem na profissão do pai percebe a escolha do magistério sendo que sua prática de ensino é conhecimento construído a partir das memórias de seu tempo de aluna. A memória desta professora permitiu conhecer um pouco sobre o início da escola pública em Lomba grande enfatizando o processo de construção de escolas isoladas, um aspecto que a distingue como professora.

Palavras-chave: Revista História da Educação Latino-americana, história oral, história da educação, memória coletiva, educação rural.

\footnotetext{
Artigo de investigação científica e tecnológico financiamento: Fundo de pesquisa Milton Valente Local de Investigação: Novo Hamburgo - Rio Grande do Sul - Brasil.

2 Doutorando em Educação UNISINOS com bolsa CAPES/Proex. Endereço: AV. UNISINOS, 950 - São Leopoldo- Rio Grande do Sul - Brasil - CEP 93022-000. Grupo de Pesquisa: História, de la Universidad Pedagógica y Tecnológica de Colombia, Política e Gestão da Escola Básica. Artículo vinculado al proyecto de investigación la Universidad en la capacitación de maestras rurales en Colombia y Guatemala SGI 1034 y proyecto Historias de vida. Maestras rurales de mediados del siglo XX y XXI en la zona cundiboyacense SGI 980 del grupo de investigación HISULA - UPTC.
} 


\section{BACKGROUND, TEACHING AND MEMOIRS OF A FEMALE EDUCATOR: FRAGMENTS OF RURAL TEACHING IN NOVO HAMBURGO/RS 1940-1969}

\begin{abstract}
This investigation aims into life facts and conclusions on education from the view of a basic school female educator whose career was developed in countryside of Novo Hamburgo/ RS between 1940 and 1969. This article is directly related to a further investigation about career development and performance of people that were educated as teachers but didn't get to work in different level classrooms in public schools at Novo Hamburgo in the rural side during 1940 y 2009.
\end{abstract}

This special work comes from analyzing teaching at different areas of the country part in Lomba Grande, areas that were part of a female educator named Gersy during her teaching methods development, we establish her story from different level classrooms. This investigation is mainly analytical by use of aural history, and some semi-structured interviews.

Theorical framework is mainly based in cultural History perspectives and memoirs as a study document. Subject of study is an educator that even though her youth and lack of experience in parenting and teaching was able to realize of her choice on teaching and her pedagogical practice that made an evidence that experience made part of knowledge building and teaching. This educator's memoirs allowed a new approach and to know about begining of public shools in Lomba Grande, emphassising into the background process of isolated schools, as a feature that identifyed her as an Educator.

Key words: Journal of Latin American Education History, oral history, history of education, collective memory, rural education.

\section{TRAYECTORIA, DOCENCIA Y MEMORIAS DE UNA MAESTRA: FRAGMENTOS DEL ENSEÑANZA RURAL EN NOVO HAMBURGO/RS 1940-1969}

\section{RESUMEN}

El objetivo de este estudio gira en torno a los hechos y las reflexiones sobre la enseñanza de la historia de una maestra de escuela primaria, cuya carrera se ha desarrollado en las zonas rurales de Novo Hamburgo/ RS entre 1940 y 1969. Este estudio está directamente relacionada con la investigación más amplia, que se ocupa de las trayectorias de los sujetos que se constituyen maestros no trabajan en aulas multigrado en las escuelas públicas de Novo Hamburgo, en la zona rural, con el marco de tiempo prolongado (1940 y 2009). En este trabajo específico, a partir de la reflexión sobre la enseñanza en diferentes localidades de la zona rural de Lomba Grande, atravesada por una maestra - Gersy en el desarrollo de su enseñanza, se centra en su historia tejida en las clases de multigrado. La investigación es cualitativa, utilizando la metodología de la historia oral, con algunas entrevistas semi-estructuradas. El marco teórico se basa en la perspectiva de la historia cultural, y los recuerdos como un documento. El profesor en cuestión, aún muy joven en la profesión del padre se da cuenta de la elección de la enseñanza y la práctica docente es, pues, evidente que el conocimiento construido por hacer la enseñanza que se desprende de la experiencia. Los recuerdos de esta maestra ha permitido conocer un poco sobre los inicios de la escuela pública en Lomba Grande haciendo hincapié en el proceso de construcción de escuelas aisladas, un aspecto que a distingue como maestra.

Palabras clave: Revista Historia de la Educación Latinoamericana, historia oral, historia de la educación, memoria colectiva, educación rural.

\section{INTRODUÇÃO}

A história da educação, principalmente, a história regional representa um campo empírico rico e ainda pouco explorado. Os estudos sobre a história da educação rural no Brasil constituem uma área de investigação que ainda se situa na "marginalidade", priorizando determinados grupos e ignorando outros, deixando à sombra grandes zonas das práticas pedagógicas e dos atores sociais, referindo-se a ênfase nos estudos sobre o espaço urbano ${ }^{3}$.

3 Dóris Bittencourt Almeida, Vozes esquecidas em horizontes rurais: histórias de professores (Rio Grande do Sul: Dissertação (Mestrado em Educação) - Programa de Pós-Graduação em Educação, Universidade Federal do Rio Grande do Sul, 2001), 241. 
Aqui se pretende problematizar uma face pouco explorada da história: reconstruir fragmentos da história da educação no meio rural no século XX partindo de memórias de uma professora primária, cuja prática docente desenvolveu-se em classes multisseriadas em Lomba Grande - Novo Hamburgo/RS, como se observa na figura I.

Figura I - Mapa de Novo Hamburgo no Estado do Rio Grande do Sul

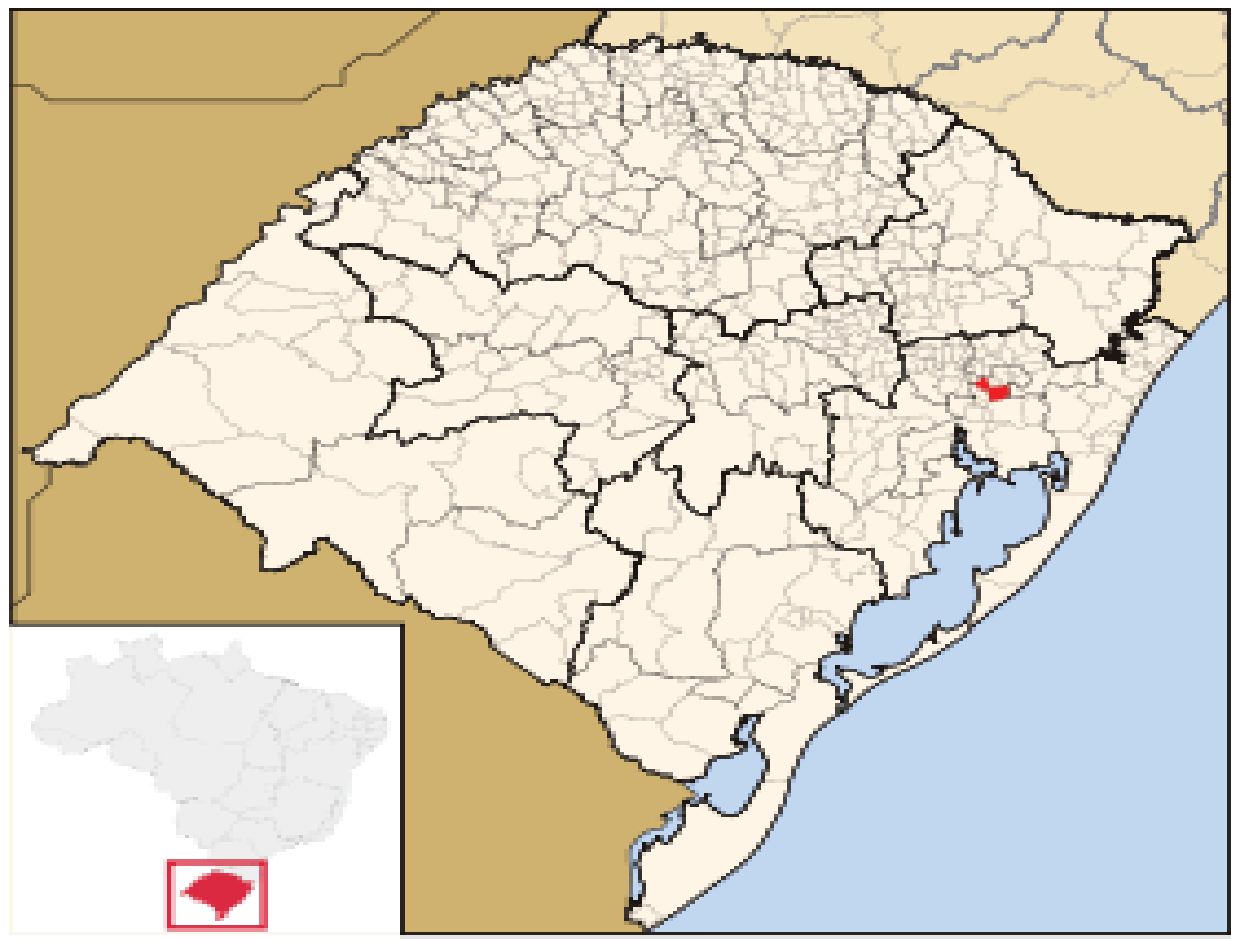

Fonte: 280px-RioGrandedoSul_Municip_NovoHamburgo.svg (2011)

Novo Hamburgo é um município gaúcho do Estado brasileiro do Rio Grande do Sul (R.S.). Localiza-se na micro-região geográfica do Vale dos Sinos distando aproximadamente 50 quilômetros da capital Porto Alegre. O presente estudo investiga através das memórias de uma professora a trajetória profissional desenvolvida na zona rural como cenário de suas práticas. A

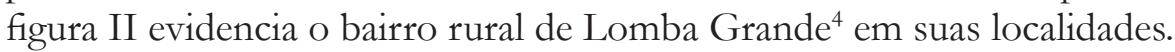

\footnotetext{
4 A origem do nome, segundo informação de antigos moradores, está ligada ao seu relevo que é ondulado, com muitos morros, diversas altitudes, onde se realizavam carreiras de cavalos. Como especificidade desse lugar em 1985 o Plano Diretor Municipal definiu um perímetro urbano para Lomba Grande de $3,5 \mathrm{~km}^{2}$, localizado na região central, em destaque na figura II e uma área rural de $148,3 \mathrm{~km}^{2}$. Sua área geográfica total compreende $156,31 \mathrm{~km}^{2}$ c.f.r Maria Martins Schütz Liene, Novo Hamburgo, sua história, sua gente. [S.1.], Novo Hamburgo, 2001. 121.
} 
FiguraII - Mapa do município de Novo Hamburgo e localidades do bairro rural Lomba Grande

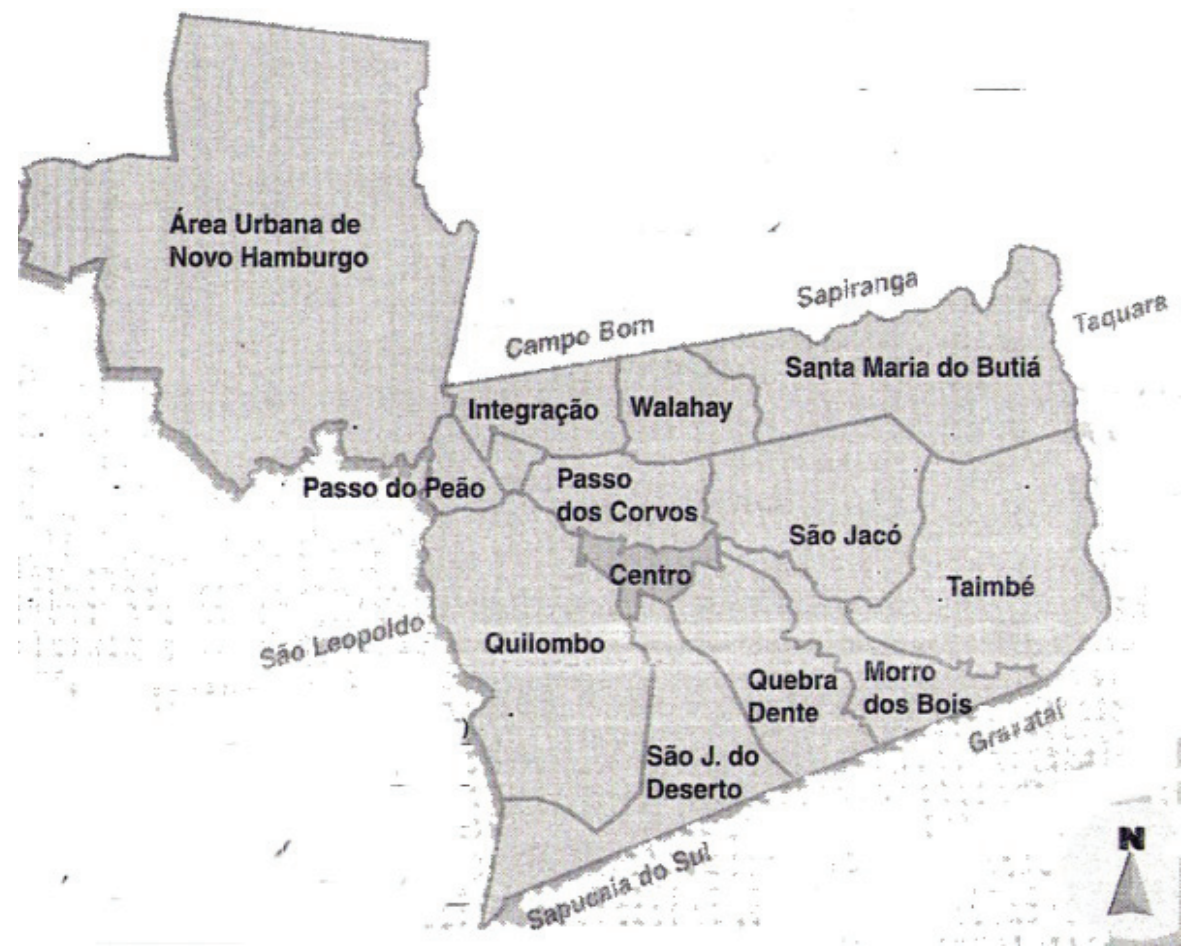

Fonte: JORNAL NH... (2005) adaptado pelo autor.

A professora Maria Gersy desenvolveu sua trajetória em diferentes localidades: região central do bairro, nas Aulas Reunidas do Grupo Escolar de Lomba Grande e no Jardim da Infância Getúlio Vargas; São Jacó, na Escola Municipal Humberto de Campos; localidade de Santa Maria na Escola Municipal Expedicionário João Moreira e no Passo dos Corvos, na Escola Municipal Castro Alves.

\section{Memória e história cultural: suas implicações com a pesquisa}

A opção teórica é pela "Nova História Cultural”, constituída a partir dos "Annales", apresentando-se como uma abordagem para se pensar a ciência histórica considerando a cultura como "[...] um conjunto de significados partilhados e construídos pelos homens para explicar o mundo" 5 . Nesta pesquisa, entende-se como História o campo de produção do conhecimento que se nutre de teorias explicativas e de fontes que corroboram para a compreensão das diferentes ações humanas no tempo e no espaço.

5 Sandra Jathay Pesavento, História \& História Cultural (Belo Horizonte: Autêntica, 2004), 15. 
A Memória, não sendo a História é entendida como uma construção social que depende do relacionamento, posição, papéis sociais do sujeito com o mundo da vida. A memória é coletiva, e nessa memória o indivíduo tem uma posição individual dos fatos vividos, mas, ela se dá pela interação entre os membros da comunidade e as experiências vivenciadas entre eles ${ }^{6}$.

A proposta desta reflexão não é reconstruir a história de vida, muito menos a história das instituições escolares no espaço rural, mas registrar as marcas da trajetória de uma professora, como sua formação e prática são reapresentadas pelas narrativas orais que emergiram nas entrevistas e como permitem recompor fragmentos da história do ensino rural em Novo Hamburgo. Neste sentido, optouse pela entrevista semi-estruturada utilizando-se da metodologia da História Oral.

Utilizou-se a entrevista "semi-estruturada" a partir de um roteiro com dez questões sobre a trajetória em classes multisseriadas Inicialmente $^{8}$ questionou-se quanto à sua primeira escolarização; seguido de momentos marcantes da docência; como a prática foi construída e quais eram os momentos de formação continuada; entre outros. A cultura, aqui entendida como campo particular de "práticas/ produções" que constituem um conjunto de significações que se materializam pelos diferentes enunciados e condutas. Dessa forma, investigam-se como as "práticas/ produções" em classes multisseriadas manifestam as apropriações culturais que foram tecidas nessa trajetória profissional. Este modo singular de trabalhar o ensino numa "parte" do município designa um conjunto de significações historicamente inscritas e que se expressam de forma simbólica num "saber-fazer" capaz de perpetuar e desenvolver a cultura, a instrução e o conhecimento?.

Em Thompson (1992) a abordagem da História a partir de evidências orais permite ressaltar elementos que, de outro modo, por outro instrumento, seriam inacessíveis. Dessa forma, as entrevistas de História Oral são tomadas como documento e servem para refletir e compreender o passado, ao lado de documentos escritos, imagens e outros tipos de registro. As entrevistas são atos de construção e de seleção de certo conhecimento da realidade e de seu funcionamento, "[...] memórias coloridas das vivências de diferentes momentos históricos e não apenas das relativas a um único espaço e período de vida dos depoentes" ${ }^{10}$.

6 Maurice Halbwachs, A Memória Coletiva (São Paulo: Ed. Centauro, 2006).

Augusto Triviños, et al., A pesquisa qualitativa na educação física: alternativas metodológicas (Porto Alegre: Editora da UFRGS, Sulina, 2004).

8 Foram realizadas duas entrevistas e três encontros com essa professora. Cada entrevista registra duas horas de gravação. Optou-se pela identificacão do sujeito conforme termo de consentimento assinado.

9 Roger Chartier, A Beira da Falésia. A história entre certezas e inquietude (Porto alegre: Editora da Universidade, UFRGS, 2002).

10 Flávia Werle et al., "Escola Normal Rural La Salle na Voz dos Ex-Alunos: sentidos e apropriações", in Educaşão rural em perspectiva internacional: instituições, práticas e formação do professor, Eds. Flávia Obino Corrêa Werle (Org.) (Ijuí: Ed. UNIJUí, 2007), 197-235. 
Ao evocar memórias é possível perceber, na trama de relações de poder, como os sujeitos se situam ao longo de suas carreiras profissionais, revelando interesses e motivações não absolutamente possíveis de tornaremse públicos anteriormente. São as "lentes", definidas pelo historiador, que a partir de memórias (documentos construídos) fará o desenho da história que se reconstrói, involuntariamente omitindo partes, ou extrapolando fatos, ou mesmo contando fragmentos de um todo maior.

\section{Formação e prática pedagógica em classes multisseriadas: fragmentos de uma trajetória docente}

A educação rural, no primeiro quartel do século XX, foi vista como um instrumento capaz de formar, de modelar um cidadão adaptado ao seu meio de origem, mas lapidado pelos conhecimentos científico endossados pelo meio urbano. As escolas rurais existiam nas mais diferentes localidades rurais no Rio Grande do Sul, inicialmente, eram de cunho religioso ou da própria comunidade. Sob influência européia, no início do século XIX, os imigrantes alemães fundaram as primeiras escolas ${ }^{11}$. Sugerem a tríade (Igreja, Escola e Cemitério), aspecto que figurava o cenário das comunidades germânicas instaladas em diferentes partes do Brasil. Os caminhos abertos pelos imigrantes originaram lugares, isso aconteceu em Lomba Grande. A construção de uma cultura local dava-se pela abertura das picadas que prepararam espaço para convivência cotidiana ${ }^{12}$. Arendt (2008) identifica esta forma original de escola como "Kolonieschulen" (Escolas rurais).

As narrativas do lugar indicaram a existência de Aulas particulares que existiram nas mais distintas localidades. Elas aconteciam, na casa dos regentes, ou em espaços cedidos, da residência dos sujeitos que, de alguma forma, destacavam-se em Lomba Grande.

A professora Gersy, destacou que o seu pai foi professor nas Aulas Públicas Federais, destaque na fotografia I. Ela rememora que o pai foi chamado pela Delegada de Ensino, para unir as Aulas e fundar as Aulas Reunidas $N^{\circ}$, no final da década de 1930; época em que Gersy iniciou sua vida escolar. $\mathrm{Na}$ década de 1940, essas Aulas Reunidas originaram o primeiro Grupo Escolar de Lomba Grande, atual Instituto Estadual de Educação Madre Benícia.

11 Lúcio Kreutz, "Escolas comunitárias de imigrantes no Brasil: instâncias de coordenação e estruturas de apoio", Revista Brasileira de Educação Rio de Janeiro Vol 1 No. 15 (2001): 159-177.

12 Isabel Arendt, Educação, religião e Identidade étnica: o Allgemeine Lebrerzeitung e a escola evangélica no Rio Grande do Sul (São Leopoldo: Oikos, 2008): 35. 


\section{Fotografia I - Aulas Públicas Reunidas de Lomba Grande, alunos} e prof. José A. Höher em 1932

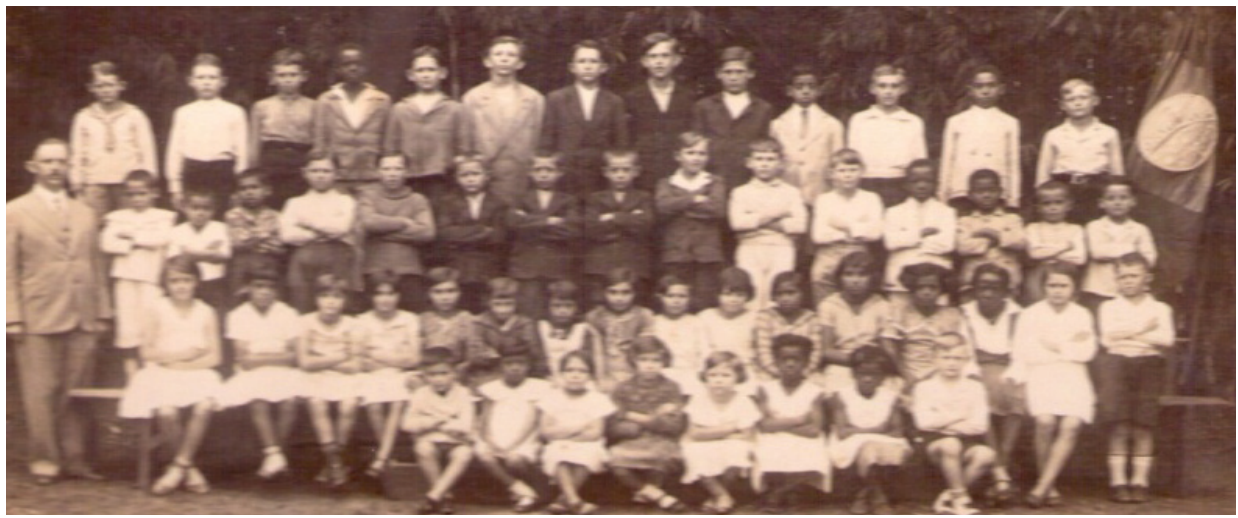

Fonte: Acervo pessoal da professora Maria Gersy Höher Thiesen, 2010.

No Grupo Escolar de Lomba Grande, Gersy aprendeu as primeiras letras, e nesse lugar também, se percebeu professora pela primeira vez. Ela recorda que havia muita disciplina e respeito ao professor. Era necessário levantar a mão e aguardar sua vez para falar. Havia muitos alunos, uns auxiliavam os outros e todos demonstravam muito interesse pela aprendizagem.

Uma prática marcante evidenciada pelas memórias dos professores foi à aula de Educação Religiosa. Era comum também, a realização de missas e/ou aulas de catequese que aconteciam, geralmente no interior, nas localidades quando recebiam, periodicamente, a visita do padre. Gersy recorda que essa prática também aconteceu na Escola Expedicionário João Moreira, conforme fotografia II, na localidade de Santa Maria. Ela e sua comadre Ilse Becker é que compravam "cucas" e ofereciam aos alunos e a comunidade que acompanhavam a missa, principalmente, no período em que a Igreja de madeira foi destruída para construção de uma nova, de alvenaria.

\section{Fotografia II1 - Alunos da Escola Municipal Expedicionário João Moreira e a prof ${ }^{a}$. Gersy, 1950}

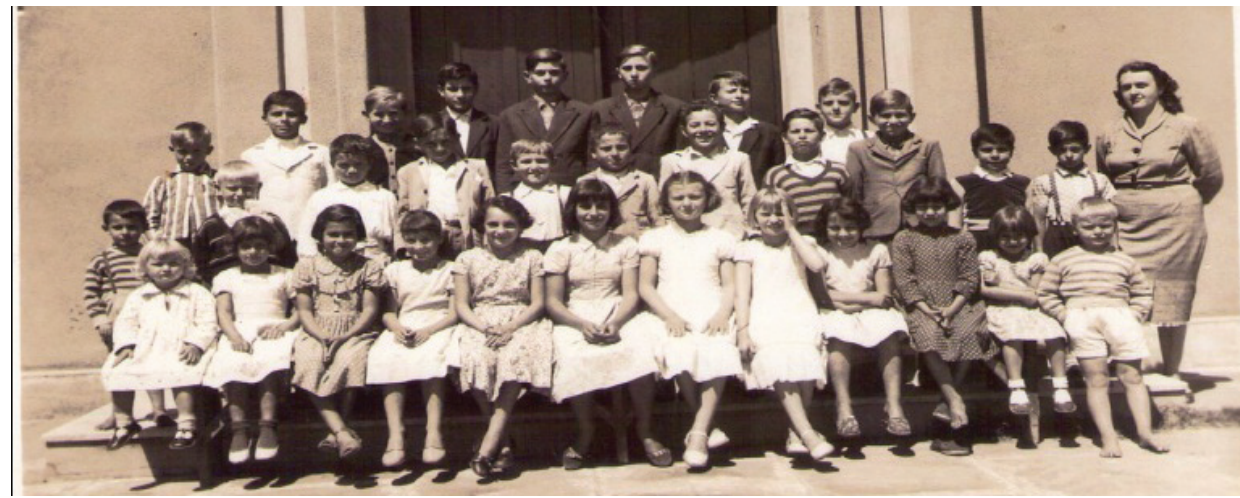

Fonte: Acervo pessoal da professora Maria Gersy Höher Thiesen, 2010. 
De modo geral, a experiência da catequese foi uma forma de experimentação docente, bem como, figurou o contexto das práticas em classes multisseriadas nas diferentes localidades de Lomba Grande. Sobre esse aspecto a professora Gersy resume "lá a Gersy também era professora, [...] pau pra toda obra, inclusive [...] vacinar eu fiz [...]. Era de catequese, era de tudo, de alfabetizar [...]". A catequese incorporava-se às atribuições docentes, até porque, a lógica operante na sociedade, caracterizava-se pela exaltação à figura do professor, em favor da vocação, da incondicional responsabilidade, que chamava pra si, em dedicar-se, de corpo e alma, à missão de preparar homens para Deus e cidadãos para a Pátria ${ }^{13}$.

As experiências de diferentes situações vividas, afetiva e emocionalmente marcantes da vida de aluno, quando criança ou na juventude, são estruturantes da vida profissional docente, existindo uma sequência de experiências que fazem à historicidade profissional. De modo especial, a trajetória dessa professora demonstrara que a docência rompeu à lógica da grande maioria, concluir a escolarização primária e trabalhar na agricultura. Gersy permaneceu na escola, como professora o que, também, demonstra a forma como valoriza o conhecimento e essa profissão ${ }^{14}$.

A maioria dos professores ingressava no magistério como auxiliar, a partir de um contrato, suprindo a existência de vaga, submetendo-se a uma prova de conhecimentos gerais que atestava a escolaridade do $5^{\circ}$ ano primário. A professora Gersy recorda "fiz um examezinho de suficiência e já comecei como professora municipal". Em 1940 ela iniciou como auxiliar do $1^{\circ}$ e do $2^{\circ}$ ano, nas Aulas Reunidas Municipais e Estaduais de Lomba Grande. Ela recorda que em 1942 foi efetivada como professora do primeiro Jardim da Infância desse bairro.

No contexto formativo de Gersy, destaca-se que a mantenedora proporcionava formação para os docentes leigos e que exerciam a docência em classe multisseriada. Nesse sentido, além das reuniões e os cursos de férias foram realizadas parcerias entre poder público e outras instituições de formação de professores como a Feevale.

O curso de férias para o Magistério municipal recebeu nomenclaturas diferentes ao longo do tempo. A investigação aos arquivos da prefeitura

\footnotetext{
13 Beatriz Terezinha Daudt Fischer, Professoras: bistórias e discursos de um passado presente (Pelotas: Seiva, 2005), 304.

14 Inácio, Maria Elizete, Práticas docente bem sucedidas: trazendo à memória o que potencializa e resignifica a teoria para um nova perspectiva da prática. In: Fórum de estudos: leituras Paulo Freire, 12, 2010. 15.
} 
municipal de Novo Hamburgo permitiu localizar alguns decretos e leis que regularam essa prática. O Decreto $\mathrm{N}^{0} 35 / 61$ parece ser o primeiro documento que instituiu oficialmente os cursos de férias. Enquanto o Decreto No 29/64 institui o curso obrigatório de férias, no período de 15 a 17 de julho de 1964, sob-responsabilidade do Departamento de Educação e Ensino. Já, o Decreto No 40/65 institui o "Curso Intensivo de Orientação e Revisão Didática” para o Magistério municipal, realizado no período de 12 a 24 de julho de 1965, em que se destacam as seguintes expressões “[...] o magistério municipal tem se distinguido pelo seu zelo e devotamento à educação primária”. Este curso não era obrigatório para as professoras efetivas, mas uma exigência para as professoras contratadas, pois "no que diz respeito às professoras contratadas [...] do seu aproveitamento dependerá a renovação do contrato no próximo ano”.

Além dos cursos, as memórias registram que havia reuniões e encontros de formação de professores municipais. A fotografia III registra um desses momentos, em 1953, no Colégio São Luiz de Novo Hamburgo.

\section{Fotografia III - Reunião de professores da RMENH, aproximadamente em 1953, Colégio São Luiz}

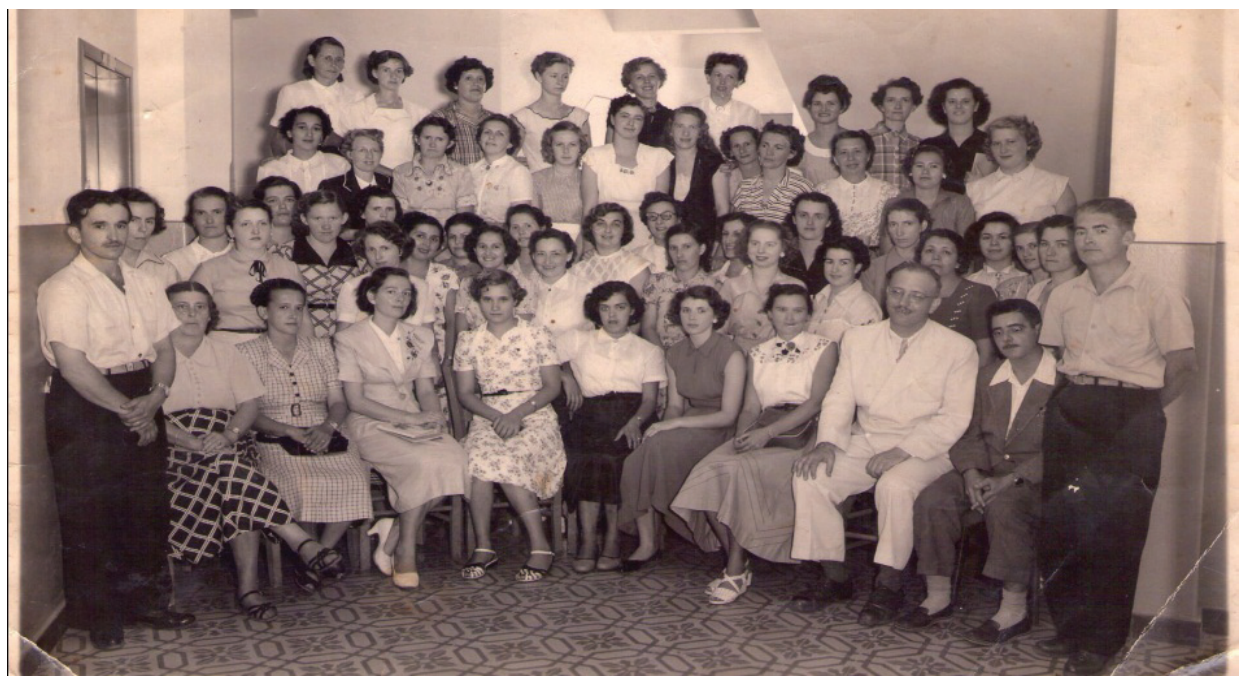

Fonte: Acervo pessoal da professora Hélia Köetz, 2010.

$\mathrm{Na}$ fotografia III, entre as autoridades presentes, destaca-se, professor Kurt Walzer - de terno branco - à frente, Maria do Carmo Schaab, ao lado do professor Kurt; a sexta - de saia preta - professora Hélia Gomes Pereira (Köetz). A terceira, na vertical, a partir do professor Kurt encontra-se vestido preto - a professora Maria Gersy Höher Thiesen. 
Quanto às memórias das práticas pedagógicas, a apropriação do modo elaborado para preparação das aulas evidencia a influências das lembranças do seu tempo de aluno. Portanto, as memórias da forma como o livro didático era utilizado em sala de aula, remetia lembrança dos questionários de pergunta e resposta propostos pelo "catecismo religioso". Observa-se, também na forma de elaboração de perguntas e respostas a influencia de uma metodologia e mentalidade de uma época, que durante muitos anos, permaneceu na escola multisseriada, como forma adequada para ensinar e desenvolver o conhecimento.

O modo de fazer a aula, mesmo no espaço rural atendia a divisão seriada dos conteúdos, proposta pela matriz urbana. Os exames finais e o acompanhamento da supervisão pedagógica da mantenedora também exigiam que o trabalho cumprisse um padrão quanto à forma de escolarização. Os professores, geralmente começavam a aula explicando as atividades que seriam desenvolvidas, utilizava-se de folhas de "papel almaço carbonado" com tarefas e exercícios, ou se utilizava do quadro verde para indicar a "lição" para os alunos de cada série. Para os alunos maiores $\left(3^{\circ}\right.$ ao $5^{\circ}$ ano) havia mais atividade para que fosse possível atender demoradamente os alunos do $1^{\circ}$ e do $2^{\circ}$ ano enfatizando o letramento. Utilizava-se do sistema de "rodízio", enquanto o quarto e quinto ano copiavam as atividades do quadro, eles tomavam lições do primeiro e segundo, em outros momentos do terceiro ano.

De modo geral, as memórias são recorrentes, quanto à responsabilidade e a "missão", que a docência comprometia cada professor. A alfabetização foi o aspecto mais importante nesse sentido. Essas formas para saber, utilizadas pelos professores na "invenção" de uma maneira para alfabetizar, que não estavam nos livros, também não estavam nas orientações de ensino dos inspetores, esse jeito se revelou apenas no exercício do fazer, aqui rememorado. Contudo, a troca de experiências, a conversa informal, que acontecia entre esses professores, nas visitas informais de final de semana, ou no encontro de "comadres" constituiuse em patrimônio diversificado de conhecimentos que se compartilhou.

Ainda no contexto do letramento a professora Gersy recordou que os alunos adoravam escutar suas histórias, portanto, a "Hora do Conto", ou a "Hora da História", aos poucos se configurou como uma prática que se incorporava ao currículo escolar, adquirindo um espaço, um dia e horário determinado para acontecer no cotidiano da escola. Gersy, "apaixonada" pelas histórias e literatura infantil inventou um modo próprio de contar histórias, como lembra.

Ligia Bohn [Orientadora] dizia que tinha que contar histórias. E eu tinha que contar histórias pros meus e os alunos da Eni. Disse a Eni: - Gersy temos que mudar 
a hora da bistória porque meus alunos não trabalham, eles cruzam os braços e estão "tesos" te escutando. E contava as histórias: Chapeuzinho Vermelho pra cima15.

Gersy recordou que, no antigo prédio da Castro Alves, uma casa de madeira, em que era possível enxergar as "frestas", sem portas (havia cortinas dividindo as salas), foi necessário realizar um ajuste no tempo da aula, que ela e sua colega Eni construíram. Esse modo de fazer, muito simples, constituiu-se em reunir todos os alunos para contar histórias. Então, "nós mudamos o horário. Todos os alunos amontoados, [...] a turma toda e a Gersy contava história. - Gersy tu transforma, tu muda a voz, tu és, tu interpreta a personagem [refere-se à fala de Eni]. Eu mudava a voz. A Eni gostava de ouvir a história”.

Além dos contos clássicos, como Chapeuzinho Vermelho e os Três Porquinhos, Gersy recordou que quando os alunos ficavam insistindo para que ela contasse mais e mais histórias, essa utilizava também, parábolas bíblicas:

\begin{abstract}
Quando foi a época da seca - e essa era bíblica - então nós fazia: os Egípcios recolheram todos os grãos e colocaram em silos grandes. Uma abelhinha disse que estava com fome. Um dia ela descobriu um pequeno furo no silo e ela voou e conseguiu trazer um grãozinho. E tava no final da manhã e eles queriam mais história e mais história, ai então ela foi avisar, entrava uma abelhinha, ela foi avisar outra abelhinha e não podia entrar de duas em duas de tão pequeno era o furinho, entrava uma abelhinha e levava um grãozinho. Voava embora, entrava outra abelhinha levava o grãozinho e voava embora e assim foi indo. De repente eles cansavam, eles tinham me cansado também. Ai D. Gersy, chega de Abelhinha, ai eu dizia não, eles só pegaram um punhadinho assim de grão [mostra com as mãos], tem muito grão pra tirar ${ }^{16}$.
\end{abstract}

Dentre as funções das escolas rurais, além de "ensinar o indivíduo a ler, a gostar de ler, a ler bastante, por exemplo, à Educação Geral", deveria desenvolver os bons hábitos de higiene; de boa saúde; saberes sobre as contas e seu uso na vida cotidiana ${ }^{17}$ Os conhecimentos de alguma coisa sobre o mundo e sua Pátria, também caracterizavam uma educação geral, que os alunos das escolas públicas deveriam receber nas escolas primárias. Esses ensinamentos serviriam como conhecimento prático, ao que ele viesse a ser mais tarde.

A professora Gersy lembrou ainda o aspecto cívico de suas práticas, uma situação que the deixou muito orgulhosa:

15 Thiesen, María Gercy Höher. Entrevista oral sobre a trajetória docente em classes multisseriadas em Lomba Grande. Novo Hamburgo, 23 de abril de 2010. Entrevista concedida a José Edimar de Souza.

16 Thiesen, Maria Gercy Höher. Entrevista oral sobre a trajetória docente em classes multisseriadas em Lomba Grande. Novo Hamburgo, 23 de abril de 2010. Entrevista concedida a José Edimar de Souza.

17 Miguel y Maria Elisabeth Blanck. "As escolas rurais e a formação de professores: a experiência do Paraná - 1946-1961" in Educasaão rural em perspectiva internacional: instituiçoess, práticas e formação do professor, Eds. Flávia Obino Corrêa Werle (Org.) (Ijuí: Ed. Unijuí, 2007), 79-99. 
Eu tinha o meu Jardim da Infancia, e eles cantavam o Hino Nacional todinho de fio a pavio. Quando o Grupo fazia uma festa o Jardim fazia parte. [...], depois a mamãe me contou: - Gersy, tu nem sabe como eu fiquei "faceira", como eu fiquei orgulhosa. Porque eu, cantando o Hino Nacional quando foi passado da primeira pra segunda estrofe, com as minhas crianças, o grupo embatucou e quase pararam o Hino Nacional junto com o professor de música. E o meu jardim, cantando o Hino Nacional. Isso, até hoje, eu sinto uma alegria quando eu me lembro da minha mãe me contando, da satisfação dela, e o povo notou!

Gersy destacou que seus alunos do Jardim da Infância, saiam-se muito bem nas aulas de Canto Orfeônico. Ela se emociona ao contar essa prática, registra que a comunidade presente, na festa cívica alusiva aos festejos da pátria percebeu que os alunos do canto coral do Grupo Escolar de Lomba Grande, "embatucaram", se perderam na letra do Hino Nacional e foram seus alunos que "seguraram" a canção. O registro dessa memória permite compreender que Gersy sempre se dedicou intensamente aos ofícios da profissão, principalmente, apropriando-se do seu dever com a nação.

Werle e Metzler ${ }^{18}$ argumentam que durante muitos anos o "entusiasmo cívico" esteve incorporado às atribuições daqueles que desejassem exercer o magistério. O sentido filosófico da profissão expresso nas memórias dos sujeitos entrevistados revela que a docência foi por eles interpretada, acima de tudo como vocação, como registrou a professora Gersy em sua despedida, ser professor significava "educar as crianças como filhos" da "Pátria amada Brasil".

A professora Gersy, também lembrou situações que acentuaram as relações de poder ${ }^{19}$, como ela resume, "sempre fiz o enfrentamento e disse o que pensava, agradando ou não às autoridades, porque fui professora”, e isso fez parte das características da sua forma de compreender o trabalho docente. Gersy lembrou que os entraves na sua trajetória docente, se referiram às relações com a Igreja e com a mantenedora.

Como uma atribuição do trabalho docente, a professora Gersy recordou que foi catequista e recebeu muitos elogios do padre que atendia a localidade, pela maneira de preparar as crianças para a primeira comunhão. Ela lembra “[...] dentro daquela sala de escola [Humberto de Campos], foi feita a $1^{\text {a }}$

18 Flávia Obino Corrêa Werle y Metzler, Ana Maria Carvalho. "En busca de Contenidos y Sentidos para la Educación Rural" in Educación rural en iberoamérica: experiencia bistórica y construcción de sentido eds. Teresa González Pérez, Oresta López (Anroart - Ediciones, 2009), 79-109.

19 O poder é, para Foucault, uma rede infinitamente complexa de micropoderes que permeiam todos os aspectos da vida social. Nesse sentido, o poder não é apenas, nem principalmente instrumento de repressão, mas de criação. Ele instaura uma verdade e, assim, cria as condições de sua própria legitimação c.f.r Edward Castelo Branco, "Fazer ver o que vemos: Michel Foucalt - por uma História diagnóstica do presente”, História Unisinos, São Leopoldo Vol 11 No 3 (2007): 321-329. 
comunhão da turma de São Jacó. [...] o padre me botou nas alturas. [...] depois eu virei o demônio porque [...] não gostou do José, porque contestou ele [...]".

Como era uma prática da década de 1950, os padres visitavam as escolas e as localidades para realizarem missas, a professora Gersy contou uma situação na qual o padre da localidade visitava a Escola Municipal Humberto de Campos. Nessa ocasião, estava o padre da localidade, o Cônego e o padre Urbano Thiesen (cunhado da professora Gersy). Ela recorda que o padre virou para o Cônego e disse "[...] este eu também ensinei a votar [...]", referindo-se ao esposo dela. A professora lembra que isso bastou, para que o padre "me perseguisse", em outros momentos.

Depois desse incidente de motivação política, outros episódios marcaram a trajetória de Gersy, quando estava na Escola Expedicionário João Moreira e foi pedir um armário para guardar os livros e materiais das suas aulas, escreveu para a Orientadora do Ensino daquele período, que era a professora Iracema Brandi Grin. "Vocês decerto sabem que as missas são realizadas dentro da minha sala de aula e eu não quero que alguém mexa nos livros e pedi então um armário. [Assovia] Só não fui pra rua porque rabo não tinha pra puxar" (Gersy). Ela recordou que alguns dias após ter enviado esse ofício, o padre da localidade falou durante a missa:

\begin{abstract}
[...] começou a baixar o pau. Eu disse, esse padre está falando pra mim. Deixa falar, eu só escutando. Quando o sino terminou a missa, o pessoal não ia logo embora e ficava as comadres conversando com os compadres. A Cecilia Fisch, professora aposentada disse: Gersy, o que é que o padre tem contra ti, tudo que ele falou olhava tez assim pra ti. Pro lado que en estava sentada. Então, mexeu no abelheiro. De tarde, a "petiça" teve que vir pra Lomba Grande, en queria botar em pratos limpos com o subprefeito, meu consogro. Estava em ponto de bala, naquele dia teria dito tudo que queria. Mas você me atendeu? Você teve medo de enfrentar a Gersy. Vim embora porque estava anoitecendo, mas a coisa não ficou assim, porque lá entre eles houve alguma coisa, enfim o meu armário veio, pude guardar os livros e continuei do mesmo modo ${ }^{20}$.
\end{abstract}

A outra situação, em que se envolveu a professora Gersy, refere-se à compra e construção de um prédio próprio para a Escola Municipal Castro Alves. Essa escola funcionava em um prédio alugado, portanto, foi necessário construir uma prática autônoma para adquirir recursos e comprar o terreno, onde atualmente se localiza a escola. Gersy recorda.

Nós fizemos reuniões de noite pra então conseguir lugar, comprar terreno. Com os nossos chás compramos o terreno da Castro Alves. Eu queria quatros salas de aula

20 Thiesen, María Gercy Höher. Entrevista oral sobre a trajetória docente em classes multisseriadas em Lomba Grande. Novo Hamburgo, 23 de abril de 2010. Entrevista concedida a José Edimar de Souza. 
e uma que era pra fazer a merenda, mas queriam só dar três de aula. E fiquei tão braba, bati o pé no chão [pausa], pois então vocês não ganham um tostão da nossa escola. Compramos o terreno. - O que vão fazer com o terreno? - Vender. - E o que vão fazer com o dinheiro? - Comer tudo em churrasco e o senhor não é convidado [referindo-se ao prefeito]. Ele deu risadas! Mas nós ganhamos quatro salas ${ }^{21}$.

Os "sonhos", para Gersy, representaram degraus a serem alcançados para qualificação do trabalho e dedicação pela comunidade lomba-grandense. As táticas elaboradas para se conseguir do prefeito aquilo que desejava, demonstra a força prática de um saber construído na docência, e na astúcia para conduzir a lógica desejada, agindo sobre a própria ação estratégica, de quem direciona e detém o poder político. Utilizando-se da "[...] esperteza no modo [...] de driblar os termos dos contratos sociais, mil maneiras de jogar o jogo do outro [...]", foi por ela estabelecido nesse momento ${ }^{22}$. Uma característica que se destacou, pelas memórias de sua trajetória foi a sua capacidade persuasiva e discursiva no enfrentamento de ideias.

O conjunto das narrativas de memórias dessa professora revela o valor da representação docente dessa época (1940-1969). Dessa forma, superar a precariedade das escolas multisseriadas "domiciliares", as estradas de "chão batido" e o enfrentamento ao padre significaram a expressão máxima que recaia sobre o "ofício do magistério", entendido por ela como vocação de ensinar e preparar “criaturas para Deus e para a Nação”. A trajetória de Gersy recupera, mesmo que de forma fragmentada uma parte importante da história do ensino rural na primeira metade do século XX, além de ressaltar que a docência transcendia apenas ensinar conhecimentos pedagógicos, implicava, sobretudo um comprometimento social e político.

\section{CONSIDERAÇÕES FINAIS}

As marcas da resistência e da ternura, aspecto que caracteriza Gersy como uma docente que lutou pela legitimação da escola pública em Lomba Grande, se evidencia também pelos seus gestos e pela forma como rememorou suas práticas. As memórias de prática docente possibilitaram conhecer um pouco do cotidiano das escolas rurais em Novo Hamburgo, entre 1940 a 1969. Constata-se que o conhecimento dos seus primeiros tempos de aluna e de como seus professores desempenhavam sua prática serviram de base para que ela construísse sua prática e fosse se apropriando dos instrumentos da cultura escolar.

\footnotetext{
21 Thiesen, Maria Gercy Höher. Entrevista oral sobre a trajetória docente em classes multisseriadas em Lomba Grande. Novo Hamburgo, 23 de abril de 2010. Entrevista concedida a José Edimar de Souza.

22 Michel de Certau, A invenção do cotidiano (Artes de fazer: Petrópolis-Vozes, 2011), 79.
} 
A apropriação das "artes do ofício" expressou-se pela rememoração do sentido e significado que Gersy atribuiu à sua trajetória, enfatizando como compreendeu e incorporou as responsabilidades profissionais, no seu tempo, que não são muito diferentes das de hoje, ensinar, incondicionalmente, cumprir a maior responsabilidade pedagógica que o professor tem: ensinar os alunos uma possível leitura da realidade. Como argumenta Fischer é possível perceber a "vocação" para a docência e o peso do apostolado, da missão de amor e sacrifício que o magistério incorporava ${ }^{23}$.

A "lição" ensinada enfatizou o letramento. A alfabetização caracterizouse como aspecto de maior responsabilidade desse professor e que também foram as lembranças que expressaram maior gratidão e reconhecimento sobre a ação docente. Seu fazer ainda revela a sensibilidade frente à realidade de construir com a comunidade a escola mostrando o lugar e a importância do conhecimento, não apenas para "pegar na enxada" ou "saber ler, escrever e contar" ${ }^{24}$ mas também como um lugar de apropriação, um lugar de poder.

\section{FONTES}

Thiesen, Maria Gercy Höher. Entrevista oral sobre a trajetória docente em classes multisseriadas em Lomba Grande. Novo Hamburgo, 23 de abril de 2010 e 13 de maio de 2010. Entrevista concedida a José Edimar de Souza.

Entrevista Thiesen, Maria Gersy Höher, Novo Hamburgo, 10 de junho de 2010.

\section{REFERÊNCIAS}

Arendt, Isabel. Educação, religião e Identidade étnica: o Allgemeine Lehrerzeitung e a escola evangélica no Rio Grande do Sul. São Leopoldo: Oikos, 2008.

Castelo Branco, Edward. "Fazer ver o que vemos: Michel Foucalt - por uma História diagnóstica do presente”. História Unisinos, São Leopoldo Vol: 11, No. 3 (2007): 321-329.

Certau, Michel de. A invenção do cotidiano. Artes de fazer. Petrópolis: Vozes, 2011.

Fischer, Beatriz Terezinha Daudt. Professoras: histórias e discursos de um passado presente. Pelotas: Seiva, 2005.

Flávia Werle et al., "Escola Normal Rural La Salle na Voz dos Ex-Alunos: sentidos e apropriações", in Educação rural em perspectiva internacional: instituições, práticas e formação do professor, Eds. Flávia Obino Corrêa Werle (Org.) (Ijuí: Ed. UNIJUİ, 2007).

Halbwachs, Maurice. A Memória Coletiva. São Paulo: Ed. Centauro, 2006.

Inácio, Maria Elizete. Práticas docente bem sucedidas: trazendo à memória o que potencializa e resignifica a teoria para um nova perspectiva da prátican: Fórum de estudos: leituras Paulo Freire, 12, (2010).

23 Fischer, "Professoras: histórias",304.

24 C.f.r. Eliane Marta Santos Teixeira Lopes, et al., 500 anos de educação no Brasil. (Belo Horizonte: Autêntica, 2000); 136. 
Jornal NH. "Novo Hamburgo: Grupo Sinos", 29 maio 2005. Jornal NH, Recorte Folha 2594, localizado na Biblioteca Pública Municipal Machado de Assis de Novo Hamburgo.

Kreutz, Lúcio. "Escolas comunitárias de imigrantes no Brasil: instâncias de coordenação e estruturas de apoio". Revista Brasileira de Educação Rio de Janeiro Vol 1 No 15 (2001): 159-177.

Lopes, Eliane Marta Santos Teixeira, Luciano Mendes de Faria Filho, Cynthia Greive Veiga (Org.) 500 anos de educação no Brasil. Belo Horizonte: Autêntica, 2000.

Miguel, Maria Elisabeth Blanck. "As escolas rurais e a formação de professores: a experiência do Paraná - 1946-1961”. In Educação rural em perspectiva internacional: instituições, práticas e formação do professor, editado por Flávia Obino Corrêa Werle (Org.) Ijuí: Ed. Unijuí, (2007), 79-99.

Novo Hamburgo. Decreto Lei No 35/61, de 24 de junho de 1961. "Institui Curso obrigatório de Férias”. Prefeitura Municipal de Novo Hamburgo, 1961.

Novo Hamburgo. Decreto Lei No 29/64, de 26 de junho de 1964. "Institui Curso obrigatório de Férias. Consulta aos Arquivos de Decretos-Leis e Portarias". Prefeitura Municipal de Novo Hamburgo, 1964.

Novo Hamburgo. Decreto Lei Nº 40/65, de 8 de julho de 1965. "Institui Curso Intensivo de Orientação e Revisão Didática”. Prefeitura Municipal de Novo Hamburgo, 1965.

Pesavento, Sandra Jathay. História \& História Cultural. Belo Horizonte: Autêntica, 2004.

Schütz, Liene Maria Martins. Novo Hamburgo, sua história, sua gente. [S.1.], Novo Hamburgo: 2001.

Thompson, Paul. A voz do passado: historia oral. Trad. Lólio Lourenço de Oliveira. Río de Janeiro: Paz e Terra, 1992.

Triviños, Augusto Nibaldo Silva, Vicente Molina Neto, Juana Maira Sancho Gil. A pesquisa qualitativa na educação física: alternativas metodológicas. Porto Alegre: Editora da UFRGS, Sulina, 2004.

Werle, Flávia Obino Corrêa y Metzler, Ana Maria Carvalho. "En busca de Contenidos y Sentidos para La Educación Rural". In Educación rural en iberoamérica: experiencia bistórica y construcción de sentido editado por Teresa González Pérez, Oresta López (Coord.) [S.l.]: Anroart - Ediciones, 2009.

Souza, José Edimar de. “Trajetória, Docência e Memórias de uma Professora: Fragmentos do Ensino Rural em Novo Hamburgo/rs (1940-1969)" Revista Historia de la Educación Latinoamericana Vol. 14 No 18, (2012): pp. 265 - 280. 